\title{
SOBRE LA TRANSICIÓN POLÍTICA ESPAÑOLA
}

PILAR FERNÁNDEZ-MIRANDA LOZANA 



\section{SOBRE LA TRANSICIÓN POLÍTICA ESPAÑOLA}

POR

\section{PILAR FERNÁNDEZ-MIRANDA LOZANA}

AgUeRo, F.: “Democracia en España y supremacia civil» en Revista Española de Investigaciones Sociológicas, n. ${ }^{\mathrm{9}} 44,1988$.

Aguiar de LuQue, J.L. y M. Aragón Reyes: «El referéndum del 15 de diciembre de 1976», en R.E.O.P., n. 48, 1977.

ÁGuila TEJERINA, R. DeL: «La transición a la democracía en España: reforma, ruptura y consenso" en Revista de Estudios Políticos, n. ${ }^{2} 25,1982$.

- "El problema del diseño político de la transición española» en Documentación Social UAM, n. $73,1988$.

ÁGUILA, R. DEL y R. MONTORO: El discurso político de la Transición española, CIS, Madrid. 1984.

AlCOCER, J.L.: Fernández-Miranda: Agonia de un Estado, Planeta, Barcelona, 1986.

Álvarez Álvarez, J.L.: España desde el Centro, Espasa Calpe, Madrid 1978.

Álvarez de Miranda, F.: Del contubernio al consenso, Planeta, Barcelona, 1981.

Alzaga, O.: La Constitución Española de 1978, Foro, Madrid, 1978.

ARAGón, M.: Constitución y Democracia, Tecnos, Madrid, 1989.

Ardant, F. y O. Duhamel: L'Espagne democratique, Press Universitaires de France, París, 1979.

AREILZA, J.M.: Diario de un ministro de la Monarquía, Planeta, Barcelona, 1979.

- Cuadernos de la Transición, Planeta, Barcelona, 1983.

- A lo largo del Siglo, Planeta, Barcelona, 1993.

ARIAS-SALGADO, R.: “Polémica sobre la interpretación de las Leyes Fundamentales: dimensión política y dimensión jurídico-técnica", en Sistema, n.ำ 5, 1974.

- “Una perspectiva de la Transición española a la democracia» en Cuenta y Razón, n. 41, 1988.

Armada, A.: Al servicio de la Corona, Planeta, Barcelona, 1983.

ARMARIO, D.: El triángulo: EI PSOE durante la Transición, F. Torres, Valencia, 1981. 
Armas Marcelo, J.J.: Los años que fuimos Marilyn, España Calpe, Madrid, 1995.

ARRESE, J.L. DE: Una etapa constituyente, Planeta, Barcelona, 1982.

ATTARD, E.: Vida y muerte de UCD, Planeta, Barcelona,. 1983.

BaEna del AlCÁzAR, M.: Los actos políticos del Gobierno en el Derecho español, Prensa del Movimiento, Madrid, 1978.

BALlBE, M.: Orden público y militarismo en la España constitucional, Alianza, Madrid, 1983.

BARLOYRA, E.A.: Comparing new democracies: Transition and consolidation in Mediterranean Europe and Southern Cone. Westview Press, 1987.

BAÑón MARTínez, R.: «El proyecto de ley de incompatibilidades de los procuradores en Cortes. Un comentario sobre la presencia en la cámara de la burocracia española", en R.E.O.P., ก. ${ }^{9} 38,1974$.

BARDABIO, J.: La crisis, Sedmay, Madrid, 1974.

- «Torcuato Fernández-Miranda" en Políticos para una crisis, Sedmay, n. $²$, MAdrid, 1974.

- El Dilema, Strips, Madrid, 1978.

- Los silencios del Rey, Strip, Madrid, 1979.

- Las claves del Rey, Espasa Calpe, Madrid, 1995.'

BARNES, S. y otros autores: "The spanish public in Political Transition», en British Journal of Political Science, n. $911,1981$.

Bau CARPI, F.: Crónica de 20 años, Cooperativa Gráfica Dertosense, Tortosa, 1991.

BAYOD, A.: Franco visto por sus ministros, Planeta, Barcelona, 1981.

BECKER, F.: «Una valoración económica del cambio político en España» en Rev. de Economía de la UAM, n. 152-153, 1991.

Bernaldez, J.M.: Ruptura o reforma, Plaza y Janés, Barcelona, 1984.

Bernales Ballesteros, E.: El camino español de la democracia, Instituto de Cooperación lberoamericana, Madrid, 1986.

BIESCAS, J.A. y M. TUÑ́N DE LARA: España bajo la dictadura franquista, Labor, Barcelona, 1980.

BORJA, J.: “Crisis del Estado autoritario. Sistema de partidos en España" en Papers, n. 8, 1978.

Borrás Betriu, R.: El Rey de los Rojos, Plaza y Janés, Barcelona, 1996.

Burns Marañón, T.: Conversaciones sobre el Rey, Plaza y Janés, Barcelona, 1995.

BUSQUETS, J.: “Las fuerzas armadas en la Transición española» en Sistema, n. 93, 1989.

CACIAGLI, M.: Elecciones y partidos en la Transición española, C.I.S., Madrid, 1986.

Calvo Serer, R.: ¿Hacia la Tercera República Española?, Plaza y Janés, Barcelona, 1977.

- Mis enfrentamientos con el poder, Plaza y Janés, Barcelona, 1978.

Calvo Sotelo, Leopoldo: Memoria viva de la Transición, Plaza y Janés, Barcelona, 1990.

CAmpos, G.: «Los dos primeros gobiernos de la Monarquía y sus relaciones con el poder económico" en Cuadernos del Ruedo lbérico, n. 51, París, 1976.

Canals Vidal, F.: Política española, pasado y futuro, Acervo, Barcelona, 1977. 
CARR, R. y J. FusI: España, de la dictadura a la democracia, Planeta, Madrid, 1979.

CarRILlo, S.: Memoria de la Transición: la vida política española y el P.C.E., Grijalbo, Barcelona, 19083.

- El año de la peluca, Ediciones B, Barcelona, 1987.

CASALI, L.: Per una definizione della dittadura franchista, Franco Angeli, Milan, 1990.

Casanova, J.: «Modernization and Democratization: Reflections on Spain's transition of democracy" en Social Research, n. 4, 1983.

Cebrián, J.L.: La España que bosteza. Apuntes para una historia crítica de la Transición, Taurus, Madrid, 1980.

Cernuda, P. y otros autores: Todo un Rey, Estudios y Ediciones, Madrid, 1981.

Cierva, R. dE LA: Crónicas de la Transición, Planeta, Barcelona, 1976.

- La cuarta apertura, Ed. Paulinas, Madrid 1976.

Historia del Franquismo, Planeta, Barcelona 1977.

C.I.T.E.P.: Ley electoral y consecuencias políticas, Madrid, 1977.

CLARK, R.P.: Spain in the 1980's: the democratic transition and a new international role, Ballinger, Washington, 1987.

Colectivo de Estudios por la Autonomia Obrera: Luchas autónomas en la Transición democrática, Zero, Bilbao, 1977.

COLECTIVO DE INFORMACión: Abstención es el voto de la oposición, E. Escobar, Madrid, 1976.

COTARELO, R. y otros autores: Transición española y consolidación democrática, España 19751986, CIS, Madrid 1992.

Coverdale, J.F.: The political transformation of Spain after Franco, Praeger, N.Y., 1979.

CHAO, R.: Después de Franco España, Felmar, Madrid, 1976.

Diaz Garcia, E.: La Transición a la democracia, claves ideológicas, 1976-1986. Eudema, Madrid, 1987.

- «Pensamiento socialista durante el franquismo» en El socialismo en España, Pablo Iglesias, Madrid, 1986.

Equipo Democracia 2000: Referendum, el test de las elecciones, Pecosa, Madrid, 1977.

EQUIPo Limite: Primer año del postfranquismo, Pecosa, Madrid, 1977.

ESTEBÁN, J. DE: «Algunas reflexiones sobre las consecuencias sociopolíticas del crecimiento económico acelerado" en Anales de Sociología, n.ํ 3, 1967.

- Por la senda constitucional, Ed. El Pais, Madrid, 1987.

Estebán, J. de y L. López Guerra: La crisis del Estado franquista, Labor, Madrid, 1977.

- El Proceso electoral, Labor, Barcelona, 1977.

- De la Dictadura a la Democracia (Diario político de un período constituyente), Sección de Publicaciones de la Universidad Complutense, F. de Derecho, Madrid, 1979.

- El régimen constitucional español. Labor, Barcelona, 1980.

- Los partidos políticos en la España actual, Planeta, Barcelona, 1982. 
ESTEBÁN, J. DE y otros autores: Desarrollo político y Constitución española, Ariel, Barcelona, 1973.

Fernandez-Braso, M.: Conversaciones con Alfonso Guerra, Planeta, Barcelona, 1983.

Fernández Carvajal, R.: La Constitución española, Editora Nacional, Madrid, 1969.

Fernández-Miranda Alonso, F.: «La ley para la Reforma Política» en Boletín de la Facultad de Derecho de la UNED, n. 0 , Madrid, 1977.

- "Los problemas de la distribución territorial del poder en España. La reforma del Senado", en Revista de Derecho Político de la UNED, n. ${ }^{2}$ 34, Madrid, 1991.

Fernández-Miranda Hevia, T.: Estado y Constitución, Espasa Calpe, Madrid, 1975.

Fernández-Miranda lozana, P. y A. Fernández-Miranda Campoamor: lo que el Rey me ha pedido. Torcuato Fernández-Miranda y la Reforma Política, Plaza y Janés, Barcelona, 1995.

FERnÁndez de LA MORA, G.: Los errores del cambio, Plaza y Janés, Barcelona, 1986.

Fernández Ordónez, F.: La España necesaria, Taurus, Barcelona, 1986.

Fontán, A.: Las Claves de la Transición. (1975-1985), Ed. Nacional, Madrid, 1985.

Fraga Iribarne, M.: Horizonte español, Ed. Nacional, Madrid, 1965.

- El desarrollo político, Gijalbo, Barcelona, 1972.

- Un objetivo nacional, Dirosa, Barcelona, 1976.

- Alianza Popular, Albia, Bilbao, 1977.

- La Constitución y otras cuestiones fundamentales, Planeta, Barcelona, 1978.

- Ideas para la reconstrucción de una España con futuro, Planeta, Barcelona 1980.

- Memoria breve de una vida pública, Planeta, Barcelona, 1983.

- En busca del tiempo servido, Planeta, Barcelona, 1987.

Franco Bahamonde, F.: El pensamiento político de Franco, Ed. del Movimiento, Madrid, 1975.

FRIEDRICH, C.J.: Constitucional Government and Democracy: Theory and practice in Europe and America, Ginn and Company, Boston, 1950. Instituto de Estudios Políticos, Madrid, 1975.

García Cotarelo, R.: "Las elecciones en la democracia: España» en Revista de Occidente, n. $91,1986$.

Garcia Escudero, J.M.: Historia política de la época de Franco, Rialp, Madrid, 1987.

García Fernández, J.: El régimen de Franco: Un análisis político, Akal, Madrid, 1976.

Garcia San Miguel, L.: Teoría de la Transición. Un análisis del Modelo Español 1973-1978, Editora Nacional, Madrid, 1981.

García Trevijano, A.: La alternativa democrática, Plaza y Janés, Barcelona, 1977.

Garrigues Díaz-Cañavate, A.: Diálogos conmigo mismo, Planeta, Barcelona, 1978.

Garrigues WALKer, J.: Una política para España, Unión Editorial, Madrid, 1976.

- Un año antes, un año después, Unión Editorial, Madrid, 1978.

GIL Robles, J.M.: La monarquía por la que luché, Taurus, Madrid, 1976. 
— Un final de jornada: 1975-1977, Tordesillas, Madrid, 1977.

Gılmour, D.: La transformación de España, Plaza y Janés, Barcelona, 1986.

GODSA: Libro blanco para la reforma democrática, Madrid, 1976.

GonzÁlez CASANova, J.A.: "Asociaciones políticas y monarquía moderada» en Españ 1974, Guadiana, Madrid, 1974.

- La lucha por la democracia en España, Avance, Barcelona, 1975.

- El cambio inacabable: 1975-1985, Anthropos, Barcelona 1986.

González FIERro, F.: «Evolución y ruptura, pasos para la democracia en España» en Revista

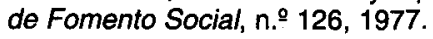

González Navarro, F.: La nueva Ley Fundamental para la Reforma Política, Colección informe, Madrid, 1977.

González Seara, L.: La década del cambio, Plaza y Janés, Barcelona, 1987.

Guerra, A.: Felpie González, de Suresnes a la Moncloa, Novatex, Madrid, 1984.

GUNTHER, R. y otros autores: Spain after Franco, the making of a competitive party sistem. CIS, Madrid, 1986.

Heras, J. de las y J. Villarín: El año de Arias. Diario Político español, Sedmay, Madrid, 1974. Hermet, G.: L'Espagne de Franco, Armand Colin, París, 1974.

HeRnández GiL, A.: El cambio político español y la Constitución, Planeta, Barcelona, 1982.

Herrero Rodríguez de Miñón, M.: El principio monárquico, Cuadernos para el Diálogo, Madrid, 1972.

- Memorias de Estio, Temas de Hoy, Madrid, 1993.

Herrero Tejedor, F.: La evolución política, Ediciones del Movimiento, Madrid, 1975.

HuneEUS, C.: La UCD y la Transición a la democracia en España, CIS, Madrid, 1985.

Huntington, S.P.: La tercera ola, Paidós, Barcelona, 1994.

IZQUierdo, A.: Yo, testigo de cargo, Planeta, Barcelona, 1981.

IZQUIERDO, M.P.: De la huelga general a las elecciones generales, De la Torre, Madrid, 1977.

JaUREGUI, F. y P. DE Vega: Crónica del antifranquismo, Argos Vergara, Barcelona, 1983.

JiMÉnez BlanCo, A.: Los niños de la guerra ya somos viejos, Unión Editorial, Madrid, 1994.

Jiménez Blanco, J.: De Franco a las Elecciones Generales: Artículos Políticos, Tecnos, Madrid, 1978.

JIMÉnez de PARGA, M.: Lo que nos pasa, Tecnos, Madrid, 1974.

Jiménez Riutord, D.: España: Ejército y Cambio, una visión militar. Miguel Font, Palma de Mallorca, 1989.

JULIA, S.: "Transiciones a la democracia en la España del siglo XX" en Sistema, n. 84, 1988.

LAMA, C. DE LA: Juan Carlos camino del Trono, Sedmay, Madrid, 1974.

LASA, F.: «La oferta de la Junta Democrática: Lenin ha muerto" en Cuadernos de Ruedo IbériCo, n. $.43,1975$. 
LETAMENDIA, P.: L'intervention des organitations partisanes transnationals dans le processus de democratisation espagnol. Centre d'Etudes et de recherche sur L'Espagne et le monde hispanique, Uiversité de Bordeaux.

LINDE Paniagua y Herrero Lera: «El referendum: de las Leyes Fundamentales al Anteproyecto de la Constitución", en R.E.P. n. ${ }^{\circ} 2,1978$.

LINZ STORCH DE GRACIA, J.J. y otros autores: Informe sociológico sobre el cambio político en España, 1975-1981, FOESSA, Madrid, 1981.

López Aranguren, J.L.: España: Una meditación política, Ariel, Barcelona, 1983.

LÓPEZ GUerRa, L.: “Abtencionismo electoral en contextos no democráticos y de transición: el caso español» en R.E.I.S. n. ${ }^{\circ} 2,1978$.

LOPEZ PINA: «Sobre la ley electoral», en Sistema, n. 16, 1977.

López Pina, A. y López Aranguren, E.: La cultura política de la España de Franco, Taurus, Madrid, 1976.

LóPEZ PINTOR, R.: La opinión pública española del franquismo a la democracia, CIS, Madrid, 1982.

LÓPEZ RODO, L.: La larga marcha hacia la monarquía, Plaza y Janés, Barcelona 1979.

- Los años decisivos, Plaza y Janés, Barcelona, 1991.

- El principio del fin, Plaza y Janés, Barcelona, 1992.

- Claves de la Transición, Plaza y Janés, Barcelona, 1993.

Lora Tamayo, M.: Lo que yo he conocido. Recuerdos de un viejo catedrático que fue ministro, Fedérico Joly y Cía., Cádiz, 1993.

LuCAS Verdú, P.: La octava Ley Fundamental, Tecnos, Madrid, 1976.

- «La singularidad del proceso constituyente español» en R.E.P. n. ${ }^{2} 1,1978$.

- "Derecho y política y transformación política española» en Revista de la Facultad de Derecho de la U.C.M., n.55, 1979.

Maravall, J.M.: La política de la Transición, Taurus, Madrid, 1985.

Maravall, J.M. y Santamaria, J.: «Crisis del franquismo, transición política y consolidación de la democracia en España” en Sistema, n.. 68-69, 1985.

MARIAS, J.: La España real, Espasa Calpe, Madrid, 1976.

- La devolución de España, Espada Calpe, Madrid, 1977.

- España en nuestras manos, Espasa Calpe, Madrid, 1978.

- Cinco años de España, Espasa Calpe, Madrid, 1982.

- España inteligible, Alianza, Madrid, 1985.

- La libertad en juego, Espasa Calpe, Madrid, 1986.

MARtín Oviedo, J.M.: «De la octava Ley Fundamental a la nueva ordenación constitucional española" en Revista de Derecho Público, 1977.

Martín SANz, D.: «En el bunker y fuera de él» en España, su inmediato futuro político, Acervo, Barcelona, 1975.

Martín Villa, R.: Al servicio del Estado, Planeta, Barcelona, 1984. 
Martínez Cuadrado, M.: Sistema político español. 1975-1979 y el comportamiento electoral en el sur de Europa 1976-1980. Instituto de Cooperación Intercontinental, 1980.

MeliA, J.: ¿Qué es la Reforma Política? La Gaya, Barcelona, 1976.

MERIDA, M.: Un Rey sin Corte, Planeta, Barcelona, 1993.

MESA, R.: Democracia y política exterior en España, Eudema, Madrid, 1988.

MigUEL, A. DE: Sociologia del franquismo, análisis ideológico de los ministros del régimen, Euros, Barcelona, 1975.

- La herencia del franqusimo, Cambio 16, Madrid, 1976.

Miguel González, S.: La preparación de la Transición a la Democracia en España, Universidad de Zaragoza, 1990.

MOA, P.: De un tiempo y un pais, Ed. la Torre, Madrid, 1982.

- “El maoísmo en España» en Cien años del hombre que cambió China, Análisis de ABC, 26-12-93.

Morán, G.: Adolfo Suárez, Historia de una ambición. Planeta, Barcelona, 1979.

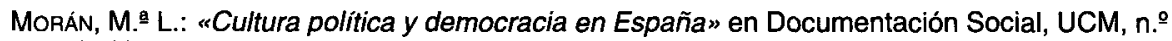
$73,1988$.

MORODO, R.: La Transición política, Tecnos, Madrid, 1985.

- Por una sociedad democrática y progresista, Turner, Guadalajara, 1982.

Moxon-Browne, E.: Political change in Spain, Routledge and Kegan Paul, Boston, 1989.

MURILLO FERROL, F.: Informe sociológico sobre el cambio social en España, Foessa, Madrid, 1983.

Navarro, J.: Nosotros, la Transición, Temas de Hoy, Madrid, 1995.

NourRy, PH.: Juan Carlos. Un roi pour les republicains, Centurion, París, 1986.

NúÑEZ LADEVEZE, L.: “La semana del referendum en la prensa madrileña» en R.E.P. n. 216, 1977.

O'DONNELL, G. y otros autores: Transiciones desde un gobierno autoritario, Buenos Aires, 1989.

OLTRA, B.: El régimen franquista, Península, Barcelona, 1978.

Ollero, C.: «Desarrollo político y Constitución española» en La España de los setenta, Moneda y Crédito, Madrid, 1974.

ONETO, J.: Arias entre dos crisis, Información y Publicaciones, Madrid, 1975.

Osorio, A.: Trayectoria Política de un Ministro de la Corona, Planeta, Barcelona, 1980.

Otero Novas, J.M.: Nuestra democracia puede morir, Plaza y Janés, Barcelona, 1987.

PALACIO ATARD, V.: Juan Carlos l y el advenimiento de la Democracia, Discurso de ingreso en la Real Academia de la Historia, Espasa Calpe, Madrid, 1988.

PAYNE, S.G.: «La Transición española desde el punto de vista histórico» en C uenta y Razón, ก.ำ 1, 1981.

Peces Barba, G.: La lzquierda y la Constitución, Barcelona, 1978.

Pérez Mateos, J.A.: La infancia desconocida de un Rey, Planeta, Barcelona, 1980.

- El Rey que vino del exilio, Planeta, Barcelona, 1981. 
Pérez TREMPS: “La Ley para la Reforma Política. Aspectos de la Transición política española» en Revista de la Facultad de Derecho de la Universidad Complutense, n. 54, 1979.

Poulantzas, N.: La crisis des Dictatures. Portugal, Grèce, Espagne, Maspero, París, 1975.

Pons Prades, E.: Crónica negra de la Transición española (1976-85), Plaza y Janés, Barcelona, 1987.

Powell, CH.: El Piloto del cambio, Planeta, Barcelona, 1991.

- Juan Carlos. Un Rey para la Democracia, Ariel/Planeta, Barcelona, 1995.

Pradera, J.: La Transición en España, 1975-1986. (Catálogo de la Exposición en el Senado: La Transición en España), Madrid, 1989.

Prego, V.: Asi se hizo la Transición, Plaza y Janés, Barcelona, 1995.

PRESTon, P.: El triunfo de la democracia en España: 1969-1982, Plaza y Janés. Barcelona, 1986.

- Franco Caudillo de España, Grijalbo, Barcelona, 1994.

Primero de Rivera, P.: Recuerdos de una vida, Dyrsa, Madrid, 1989.

RAmírez, L.: Del franquismo a la predemocracia, El viejo topo. Barcelona, 1980.

RAMiREZ JiMÉnEZ, M.: España 1939-1975: régimen político e ideologia, Guadarrama, Madrid, 1978.

Ramírez, P.J.: Asi se ganaron las elecciones, Prensa Española, Madrid, 1979.

RECIO, J.L. y otros autores: Para comprender la Transición española: política y religión, Verbo Divino, Estella, 1990.

REINARES, F.: "Terrorismo y Transición a la democracia en España" en Revista de Occidente, n. $.54,1985$.

RODRíguez DiAz, A.: Transición política y consolidación constitucional de los partidos políticos, Centro de Estudios Constitucionales, Madrid, 1989.

ROMERo, E.: Tragicomedia de España, Planeta, Barcelona, 1985.

- Retratos de Época, Plaza y Janés, Barcelona, 1985.

- Papeles reservados, Plaza y Janés, Barcelona, 1986.

SaInz Rodriguez, P.: Un reinado en la sombra, Planeta, Barcelona, 1981.

Salmador, V.: Las dos Españas y el Rey, Edilibro, Madrid, 1981.

SÁnChez Agesta, L.: La nueva Ley para la Reforma Política, Presidencia de Gobierno, Madrid, 1977.

SAN MARTín, J.I.: Servicio Especial: A las ordenes de Carrero Blanco, Planeta, Barcelona, 1983.

SANTAMARiA, J.: «Transición controlada y dificultades de consolidación» en Transición a la Democracia en el sur de Europa y América Latina, CIS, Madrid, 1981.

Sarasqueta, A.: De Franco a Felipe, España 1975-1985, Plaza y Janés, Barcelona 1984.

Seco Serrano, C.: Juan Carlos l, el Rey que reencontró América, Anaya, Madrid, 1989.

Serrano, C.: Otra España: documentos para un análisis, 1974-89, Diputación de Alicante, 1990.

Silva Muñoz, F.: Memorias políticas, Planeta, Barcelona, 1993.

Soriano, M.: Sabino Fernández Campo. La sombra del Rey, Temas de Hoy, Madrid, 1995. 
Sotelo, I.: Los socialistas en el poder, El Pais, Madrid, 1986.

- Tácito, Ibérico-Europea de Ediciones, Madrid, 1975.

Tezanos, J.F., Ramón Cotarelo y Andrés DE BLAS: La Transición democrática española, Sistema, Madrid, 1989.

Tierno Galván, E.: Cabos sueltos, Unión Editorial, Madrid, 1984.

TOQUERo, J.M.: Franco y Don Juan, la oposición monárquica al franquismo, Plaza y Janés, Barcelona 1989.

- Don Juan de Borbón, el Rey padre, Plaza y Janés, Barcelona, 1993.

TORRE GOMEZ, H. DE LA: Portugal y España en el cambio político: 1958-1978, Universidad Nacional de Educación a Distancia, Madrid, 1989.

TUÑón DE LARA y otros autores: Historia de España: Transición y Democracia, Labor, Barcelona, 1991.

Tussell, J.: La oposición democrática al franquismo, Planeta, Barcelona, 1977.

- Los hijos de la sangre: España 1936-1986, Espasa Calpe, Madrid, 1986.

- La Dictadura de Franco, Alianza, Madrid, 1988.

- "La Transición española a la Democracia desde un punto de vista comparativo" en Cuenta y Razón, n.. 41, 1988

- La España de Franco, Historia 16, Madrid, 1989.

- La Transición española a la democracia, Historia 16, n. 31.

- Carrero Blanco. La eminencia gris del régimen de Franco, Temas de Hoy, Madrid, 1993.

- Juan Carlos I, Temas de Hoy, Madrid, 1995.

Utrera Molina, J.: Sin cambiar de bandera, Planeta, Barcelona, 1989.

VAN HALEN, J.: Objetivo: Ganar el Futuro. Conversaciones con Alfonso Osorio, Plaza y Janés, Barcelona, 1986.

Vázouez Montalbán, M.: La democracia paso a paso, Cotal, Barcelona, 1979.

VEGA, P. DE: «Fuerzas políticas y tendencias ideológicas en los últimos años del franquismo» en La España de los 70, Vol. III, El Estado y la Política, Moneda y Crédito, Madrid, 1974.

- "La Transición política a la luz de los principios democráticos de legalidad, publicidad y racionalidad" en Las experiencias del proceso constitucional en México y España, Universidad Autónoma de México, México, 1979.

- La Reforma Constitucional y la problemática del poder constituyente, Tecnos, Madrid, 1985.

VIDAL Beneyto, J.: España a debate, Tecnos, Madrid, 1991.

VILALLONGA, J.L.: EI Rey, Plaza y Janés, Barcelona, 1993.

VILLAR, S.: La década sorprendente 1976-1986, Planeta, Barcelona, 1986.

VIÑAS, A.: La destrucción de la democracia en España, Historia 16, Madrid, 1979.

Vizcaino CaSAS, F.: 1975, el año que Franco murió en la cama, Plaza y Janés, Barcelona, 1992.

- 1973, el año que volaron a Carrero Blanco, Planeta, Barcelona, 1993.

YSART, F.: Quién hizo el cambio, Argos-Vergara, Barcelona, 1984. 